\title{
Comparison of Various Databases for Estimation of Dietary Polyphenol Intake in the Population of Polish Adults
}

\author{
Anna M. Witkowska ${ }^{1, *}$, Małgorzata E. Zujko ${ }^{1}$, Anna Waśkiewicz ${ }^{2}$, Katarzyna M. Terlikowska ${ }^{1}$ \\ and Walerian Piotrowski ${ }^{2}$ \\ Received: 31 August 2015 ; Accepted: 16 October 2015 ; Published: 11 November 2015 \\ 1 Department of Food Commodities Science and Technology, Medical University, Szpitalna 37, Bialystok 15-295, \\ Poland; malgorzata.zujko@umb.edu.pl (M.E.Z.); katarzyna.terlikowska@umb.edu.pl (K.M.T.) \\ 2 Department of Epidemiology, Cardiovascular Disease Prevention and Health Promotion, \\ Institute of Cardiology, Niemodlińska 33, Warsaw 04-635, Poland; awaskiewicz@ikard.pl (A.W.); \\ wpiotrowski@ikard.pl (W.P.) \\ * Correspondence: witam@umb.edu.pl; Tel.: +48-85-686-5088; Fax: +48-85-686-5089
}

\begin{abstract}
The primary aim of the study was to estimate the consumption of polyphenols in a population of 6661 subjects aged between 20 and 74 years representing a cross-section of the Polish society, and the second objective was to compare the intakes of flavonoids calculated on the basis of the two commonly used databases. Daily food consumption data were collected in 2003-2005 using a single 24-hour dietary recall. Intake of total polyphenols was estimated using an online Phenol-Explorer database, and flavonoid intake was determined using following data sources: the United States Department of Agriculture (USDA) database combined of flavonoid and isoflavone databases, and the Phenol-Explorer database. Total polyphenol intake, which was calculated with the Phenol-Explorer database, was $989 \mathrm{mg} /$ day with the major contributions of phenolic acids $556 \mathrm{mg} /$ day and flavonoids $403.5 \mathrm{mg} /$ day. The flavonoid intake calculated on the basis of the USDA databases was $525 \mathrm{mg} /$ day. This study found that tea is the primary source of polyphenols and flavonoids for the studied population, including mainly flavanols, while coffee is the most important contributor of phenolic acids, mostly hydroxycinnamic acids. Our study also demonstrated that flavonoid intakes estimated according to various databases may substantially differ. Further work should be undertaken to expand polyphenol databases to better reflect their food contents.
\end{abstract}

Keywords: polyphenols; flavonoids; databases; intake; adults

\section{Introduction}

A number of studies indicate plant foods as particularly beneficial for the prevention of heart disease [1]. Plant-based foods provide multiple bioactive components including vitamin C, E, and polyphenols, which may reduce the risk of cardiovascular diseases. A large group of these compounds, polyphenols, deserve a special attention. Polyphenols are ubiquitous secondary plant metabolites that share common molecular structure of phenol rings, which may be attached to each other or via linkages in various configurations [2]. They are members of four compound classes: flavonoids, phenolic acids, stilbenes and lignans [1]. To date, more than 500 dietary polyphenols have been described in the literature [3]. The two most prominent classes of polyphenols are flavonoids and phenolic acids. Structurally, flavonoids possess at least two phenol rings. On the basis of differences in molecular conformation, six subclasses of compounds can be distinguished: anthocyanins, flavones, flavanones, flavonols, flavanols, and isoflavones [2]. Flavonoids are characterized by 
antioxidant, antitumor and antiproliferative activities [4]. The predominant dietary sources of flavonoids are tea and fruits. Until now, there have not been specified dietary requirements regarding flavonoid intakes in humans [5]. Phenolic acids, which are widely found in nature, are hydroxy derivatives of the two major compounds: cinnamic and benzoic acids [6]. Hydroxycinnamic acids are known as potent chain-breaking antioxidants, which act by scavenging free radicals via donating hydrogen atoms and electrons [7]. Hydroxycinnamates are present in considerable amounts in such foods as coffee, tea, fruits, vegetables, and whole grains [7].

There are several databases of polyphenol contents in foods. The most commonly used polyphenol data sources are USDA databases of predominant flavonoids [8,9] and an online Phenol-Explorer database of different polyphenols [10,11]. Both data sources are systematically extended to reflect most accurately phenolic contents in food. Use of the two databases, however, has some limitations, that allow only for the estimation of dietary polyphenols, but do not give the definitive values. For that reason, a comparison of the results obtained on the basis of the various data sources may differ.

Polyphenol intake among populations is variable and depends mostly on the food preferences of individual populations. Numerous studies have shown that it can vary within quite a broad range [12,13]. Intake of flavonoids and polyphenols in the general Polish population had not yet been evaluated on the basis of the previously mentioned databases. Therefore, the primary aim of the study was to estimate the consumption of polyphenols in a population representing a cross-section of the Polish society, and the second objective was to compare the intakes of flavonoids calculated on the basis of these two commonly used databases.

\section{Materials and Methods}

\subsection{Participants}

The Polish National Multicenter Health Survey (WOBASZ) is a cross-sectional study representative for the general Polish adult population aged between 20 and 74 years. This study was carried out by the National Institute of Cardiology, Warsaw, Poland, in the years 2003-2005, in collaboration with five Polish medical universities. The response rate was $76.8 \%$. The general assessment involved a sample of more than 13,500 participants (Figure 1). Among this group approximately $50 \%$ randomly selected subjects took part in the dietary assessment. Written informed consent was obtained from all participants. The WOBASZ study obtained approval from the Bioethics Committee of the National Institute of Cardiology (no. 708). The rationale, design and methods of the WOBASZ study were described in detail elsewhere $[14,15]$. Description of selection procedure was introduced in our previous paper [16].

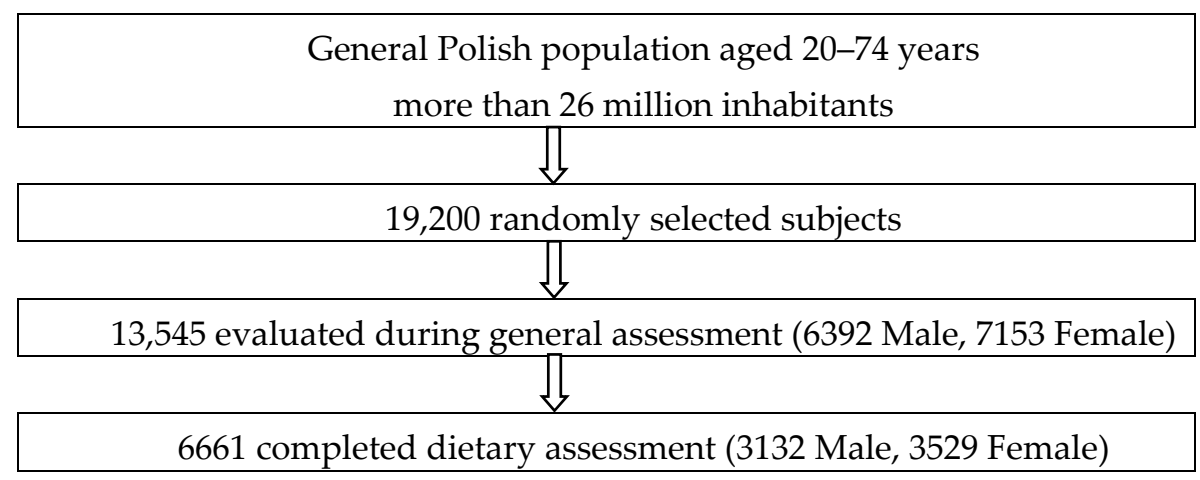

Figure 1. Flow-chart of study participants.

A standardized questionnaire was designed to collect such data as social, demographic, and economic status, physical activity, smoking habit, commune size, marital status, level of education, 
and net household per-capita income. Height and body mass measurements were taken by the personnel trained in the standard procedures. The body mass index (BMI) was calculated from weight in kilograms divided by the square of height in meters.

Blood pressure (BP) was measured three times on the right arm after 5 min of resting in a sitting position in one-minute intervals and the final BP was provided as an average of the 2nd and 3rd measurements. General description of the study group is given in Table 1.

Table 1. General description of the studied population.

\begin{tabular}{|c|c|}
\hline Number of Participants (Gender) & $n=6661$ (3132 Male, 3529 Female $)$ \\
\hline Age (year) (mean \pm SD) & $45.2 \pm 15.1$ \\
\hline $\mathrm{BMI}\left(\mathrm{kg} / \mathrm{m}^{2}\right)($ mean $\pm \mathrm{SD})$ & $26.4 \pm 5.2$ \\
\hline Systolic Blood Pressure $(\mathrm{mmHg})($ mean $\pm \mathrm{SD})$ & $133.6 \pm 20.9$ \\
\hline Diastolic Blood Pressure $(\mathrm{mmHg})($ mean $\pm \mathrm{SD})$ & $82.5 \pm 11.9$ \\
\hline Smoking $(\%)^{1}$ & 31.7 \\
\hline \multicolumn{2}{|l|}{ Age groups (\%) } \\
\hline 20-40 years & 37.8 \\
\hline $41-60$ years & 43.9 \\
\hline 61-74 years & 18.3 \\
\hline \multicolumn{2}{|l|}{ Physical activity $(\%)^{2}$} \\
\hline Low level & 35.7 \\
\hline Middle level & 16.0 \\
\hline High level & 48.3 \\
\hline \multicolumn{2}{|l|}{ Commune size $(\%)$} \\
\hline$<8,000$ inhabitants & 36.7 \\
\hline $8,000-40,000$ inhabitants & 35.5 \\
\hline$>40,000$ inhabitants & 27.8 \\
\hline \multicolumn{2}{|l|}{ Marital status $(\%)^{3}$} \\
\hline Married & 71.2 \\
\hline Single & 28.8 \\
\hline \multicolumn{2}{|l|}{ Level of education $(\%)^{4}$} \\
\hline Under middle & 55.8 \\
\hline Middle & 34.0 \\
\hline High & 10.2 \\
\hline \multicolumn{2}{|l|}{ Household per capita income $(\%)^{5}$} \\
\hline Low & 90.3 \\
\hline Middle & 6.9 \\
\hline High & 2.8 \\
\hline Energy intake (kcal/day) (mean \pm SD) & $2061 \pm 949$ \\
\hline
\end{tabular}

${ }^{1}$ smoking at least one cigarette a day; ${ }^{2}$ physical activity at leisure: low level-no such physical activity, for example jogging, cycling, swimming, gardening for at least $30 \mathrm{~min}$ a day; middle level—physical activity once a week or less; high level—everyday, almost every day or every second or third day; ${ }^{3}$ singles: widows/widowers, unmarried, divorced, in separation; ${ }^{4}$ education level: under middle-no education, partial or completed education for primary level, vocational lower secondary education, partial secondary education; middle — secondary education, partial academic education; high-tertiary education; ${ }^{5}$ calculated on the basis of the income reported by the study participants. These calculations were taken only those individuals who reported their income.

\subsection{Dietary Assessment}

Daily food consumption data were collected by trained interviewers using a single 24-hour dietary recall. On the basis of the dietary recalls completed by 6661 subjects, it was found that 125 food items and beverages consumed by the participants were sources of polyphenol intakes. These products were grouped in 9 food categories: alcoholic beverages, cereals, cocoa products, fruit, legumes, non-alcoholic beverages, nuts and seeds, oils, and vegetables (listed in alphabetical order). Complex dishes have been split into individual components. These components in which the polyphenols are present, have been taken into consideration. For example, refined wheat flour, which is a component used in typical Polish dishes such as noodles or dumplings, was separated 
using recipes of dishes contained in Polish Food Composition Tables [17]. These recipes give the amounts of food products required for $100 \mathrm{~g}$ dish portion, with consideration of yield factors. For the calculation of polyphenol/flavonoid contents by different databases, the same food items and the same culinary techniques were taken into account.

\subsection{Estimation of Dietary Polyphenol Intakes}

Intake of total polyphenols was estimated using an online Phenol-Explorer database [10], which contains mean representative content values for 502 individual polyphenols belonging to four polyphenol classes (flavonoids, phenolic acids, lignans, and stilbenes) and other polyphenols (including, among others, tyrosols) in 452 food products [11]. Flavonoids included anthocyanins, chalcones, dihydrochalcones, dihydroflavonols, flavanols, flavanones, flavones, flavonols, and isoflavones (listed in alphabetical order); phenolic acids included hydroxybenzoic acids, hydroxycinnamic acids, and hydroxyphenacetic acids; and the remaining polyphenols included lignans, stilbenes, others.

The high performance liquid chromatography (HPLC) data were used to calculate the results. For the analysis of lignans, which cannot be released with normal extraction conditions, the data obtained with HPLC method, which applies acid hydrolysis, were used.

Dietary flavonoid intake was determined using following data sources: the USDA database combined of flavonoid [8] and isoflavone [9] databases, and the Phenol-Explorer database. The USDA Database for the Flavonoid Content of Selected Foods, release 3.1 (May 2014), reports 26 predominant flavonoids in 500 food items, and the USDA Database For Isoflavone Content Of Selected Food Items, release 2.0 (September 2008) contains data for the total as well for 6 specified isoflavones (daidzein, genistein, glycitein, coumestrol, biochanin A, and formononetin) in 557 food items [9].

The meal preparation techniques were taken into consideration as factors influencing polyphenol contents in food items. The USDA databases show data both for raw and processed food items taking into account different preparation techniques. For the data obtained with Phenol-Explorer, the retention factors (RFs) were used to convert polyphenol contents in raw foods to the contents found in the processed foods. The content of polyphenols in the raw food was multiplied by appropriate RF specific for such culinary techniques as boiling, frying, or baking. These polyphenol RFs are implemented in the Phenol-Explorer database.

Eventually, polyphenol/flavonoid daily intakes were determined by multiplying the daily consumption of individual food items by polyphenol/flavonoid contents in these food items. The data for individual classes of polyphenols and the subclasses of flavonoids are expressed as aglycone equivalents.

\subsection{Data Analysis}

Data analyses were processed using Statistical Analysis System (SAS, version 9.2, SAS Institute Inc., Cary, NC, USA). Results were analyzed using the PROC GLM procedure. Analysis of covariance (ANCOVA) adjusted for season was used to determine LSMEANS for nutritional factors. The variable "season" was introduced to the model as a confounding factor to eliminate its impact on food consumption.

Dietary polyphenol and flavonoid intakes were expressed as means and standard deviations ( \pm SD). Contributions of individual classes of polyphenols, including subclasses of flavonoids, to the total polyphenol intake and the contributions of food categories and individual food items to intakes of particular flavonoids and polyphenols were presented as percentages. To compare mean values of the analyzed factors a paired $t$-Student's test was used. $p$ values less than 0.05 were considered statistically significant. 


\section{Results}

Total polyphenol intake that was calculated with the Phenol-Explorer database for the studied cross-section of the Polish society was calculated as aglycone equivalents, which amounted to $989 \mathrm{mg} /$ day with the highest contribution of phenolic acids $556 \mathrm{mg} /$ day (56\%) and flavonoids $403.5 \mathrm{mg} /$ day ( 41\%) (Table 2). The consumption of lignans, stilbenes and other polyphenols was minor $29.5 \mathrm{mg} /$ day (3\% of total polyphenols). The flavonoid intake calculated on the basis of the USDA databases [8,9] amounted to $525 \mathrm{mg} /$ day and has been found 30\% higher as compared to the data on flavonoids estimated using Phenol-Explorer ( $p$ value less than 0.001 ). The USDA databases do not contain data on phenolic acids, lignans, stilbenes and other polyphenols.

Table 2. Polyphenol intake (mg/day) in the studied population $(n=6661)$.

\begin{tabular}{|c|c|c|c|c|}
\hline & \multicolumn{2}{|c|}{ USDA Flavonoid Database * } & \multicolumn{2}{|c|}{ Phenol-Explorer } \\
\hline & mg/day (mean $\pm S D)$ & $\begin{array}{l}\% \text { Contribution to total } \\
\text { polyphenol intake }\end{array}$ & mg/day (mean $\pm S D)$ & $\begin{array}{l}\% \text { Contribution to total } \\
\text { polyphenol intake }\end{array}$ \\
\hline Flavonoids & $524.6 \pm 155^{* *}$ & unknown & $403.5 \pm 150^{* *}$ & 40.8 \\
\hline $\begin{array}{l}\text { Lignans, stilbenes, other } \\
\text { polyphenols }\end{array}$ & - & - & $29.5 \pm 9$ & 3.0 \\
\hline TOTAL polyphenol intake & - & - & $989.3 \pm 360$ & 100 \\
\hline
\end{tabular}

According to Phenol-Explorer, non-alcoholic beverages were main dietary sources of total polyphenols $743.68 \mathrm{mg} /$ day (75\% of total polyphenols) including phenolic acids $422.13 \mathrm{mg} / \mathrm{day}$ (76\% of phenolic acids) (Table 3). Moreover, according to both data sources, Phenol-Explorer and the USDA database, non-alcoholic beverages were also main dietary sources of flavonoids $316.91 \mathrm{mg} /$ day (78.5\% of flavonoids) and $471.00 \mathrm{mg} /$ day (90\% of flavonoids), respectively. Important polyphenol, flavonoid (according to both databases) and phenolic acid sources were also fruits and vegetables. Major discrepancies between the flavonoid intakes established with the USDA databases and Phenol-Explorer were found for almost all food groups ( $p$ values less than 0.001). The greatest differences were observed in the case of cereal products. The flavonoid intake from cereals, calculated with the Phenol-Explorer, exceeded more than 30 times this calculated using the USDA databases.

Table 3. Contributions of food categories to flavonoid, phenolic acid and total polyphenol intakes (mg/day) $(n=6661)$.

\begin{tabular}{|c|c|c|c|c|c|c|}
\hline \multirow[t]{2}{*}{ Food Categories } & \multicolumn{2}{|c|}{ Flavonoids (mg/day) (mean $\pm S D)$} & \multicolumn{2}{|c|}{$\begin{array}{l}\text { Phenolic Acids (mg/day) } \\
\text { (mean } \pm \text { SD) }\end{array}$} & \multicolumn{2}{|c|}{$\begin{array}{c}\text { Total Polyphenols } \\
\text { (mg/day) (mean } \pm \text { SD) }\end{array}$} \\
\hline & USDA * & Phenol-Explorer & USDA & Phenol-Explorer & USDA & Phenol-Explorer \\
\hline Alcoholic beverages & $1.00 \pm 1.46^{* *}$ & $1.24 \pm 3.10^{* *}$ & - & $1.41 \pm 1.43$ & - & $2.92 \pm 2.60$ \\
\hline Cereals & $0.11 \pm 0.13^{* *}$ & $3.84 \pm 2.22 * *$ & - & $2.44 \pm 2.43$ & - & $17.66 \pm 8.24$ \\
\hline Cocoa products & $0.67 \pm 3.51^{* *}$ & $2.69 \pm 8.05^{* *}$ & - & $0.17 \pm 0.91$ & - & $2.87 \pm 6.22$ \\
\hline Fruit & $39.09 \pm 35.49^{* *}$ & $74.82 \pm 56.56^{* *}$ & - & $39.45 \pm 75.00$ & - & $114.72 \pm 54.26$ \\
\hline Legumes & $0.20 \pm 1.93^{* *}$ & $1.53 \pm 2.27^{* *}$ & - & $0.06 \pm 0.15$ & - & $1.59 \pm 1.76$ \\
\hline Non-alcoholic beverages & $471.00 \pm 128.42 * *$ & $316.91 \pm 70.42 * *$ & - & $422.13 \pm 229.95$ & - & $743.68 \pm 116.40$ \\
\hline Nuts and seeds & $0.01 \pm 0.13$ & $0.01 \pm 0.10$ & - & $1.37 \pm 10.12$ & - & $1.39 \pm 4.97$ \\
\hline Oils & $0.12 \pm 0.10$ & $0 \pm 0$ & - & $0.17 \pm 0.07$ & - & $1.21 \pm 0.50$ \\
\hline Vegetables & $12.53 \pm 6.30^{* *}$ & $2.31 \pm 5.19^{* *}$ & - & $89.12 \pm 49.52$ & - & $103.24 \pm 24.47$ \\
\hline
\end{tabular}

Though Phenol-Explorer gives the higher results for alcoholic beverages, cereals, cocoa products, fruit and legumes, the flavonoid content of non-alcoholic beverages (mostly tea) and of vegetables, provided by the USDA databases, cause that total flavonoid intake assessed with the USDA databases is higher than this estimated with Phenol-Explorer.

According to the USDA flavonoid databases, flavanols were predominant dietary flavonoid sources $461.79 \mathrm{mg} /$ day (88\% of total flavonoids) for the studied population, followed by flavonols 
$31.95 \mathrm{mg}$ /day (6.1\%) and anthocyanins $20.93 \mathrm{mg} /$ day (4.0\%) (Table 4). Other flavonoids such as flavanones, flavones and isoflavones provided $9.95 \mathrm{mg} /$ day $(1.85 \%)$. Tea consumption accounted for more than $96 \%$ of flavanol intake. The major source of flavonols, $\sim 50 \%$, was tea, whereas for anthocyanins they were plums at about $30 \%$. Generally, the main sources of total flavonoids for the studied population were: tea $(87.1 \%)$, apples $(2.97 \%)$, plums $(1.18 \%)$ and orange juice $(1.01 \%)$.

Table 4. Dietary flavonoid intakes calculated with the USDA database * and their major food contributors $(n=6661)$.

\begin{tabular}{|c|c|c|c|}
\hline Flavonoid Class & $\begin{array}{l}\text { Flavonoid Intake } \\
\text { mg/day (mean } \pm \text { SD) }\end{array}$ & $\begin{array}{l}\% \text { of Total } \\
\text { Flavonoids }\end{array}$ & $\begin{array}{l}\text { Major Food Contributors to Flavonoid Intakes from } \\
\text { Individual Flavonoid Subclasses (\%) }\end{array}$ \\
\hline Anthocyanins & $20.93 \pm 31.37$ & 4.0 & $\begin{array}{l}\text { plums (29.5), blackcurrant juice (15.3), } \\
\text { strawberries (14.6), red currant (10.6) }\end{array}$ \\
\hline Flavanols & $461.79 \pm 108.15$ & 88.0 & tea $(96.4)$, apples $(2.3)$ \\
\hline Flavanones & $9.16 \pm 15.50$ & 1.7 & orange juice (57.6), oranges (14.3), grapefruit juice (6.8) \\
\hline Flavones & $0.63 \pm 0.51$ & 0.12 & $\begin{array}{c}\text { celeriac (24.0), apples (22.0), Savoy cabbage (11.0), } \\
\text { green pepper (8.4) }\end{array}$ \\
\hline Flavonols & $31.95 \pm 5.95$ & 6.1 & tea (47.1), apples (15.1), onion (11.4), potatoes (10.8) \\
\hline Isoflavones & $0.16 \pm 0.88$ & 0.03 & coffee $(41.2)$, soy flour $(16.8)$, soybeans (16.2) \\
\hline
\end{tabular}

In Table 5, polyphenol intakes and their main dietary sources are listed with regard to particular classes and subclasses of polyphenols. Of the flavonoids, quantitatively, the largest groups were flavanols, $314.68 \mathrm{mg} /$ day (78\% of flavonoids), followed by flavonols, $47.91 \mathrm{mg} /$ day $(11.9 \%)$, and anthocyanins, $22.03 \mathrm{mg} /$ day (5.5\%). Other flavonoids provided $18.73 \mathrm{mg} /$ day (4.6\%). When it comes to the sources of listed subclasses of flavonoids, tea was predominant source of flavanols $(86.3 \%)$ and flavonols $(72.2 \%)$, while strawberries $(37.6 \%)$, plums $(23.9 \%)$ and sweet cherries $(16.2 \%)$ were the main sources of anthocyanins. Quantitatively, the largest sources of total flavonoids for the study group were: tea $(75.9 \%)$, apples $(10.5 \%)$, plums $(2.6 \%)$, and strawberries $(2.1 \%)$.

Another group of polyphenols, phenolic acids, were most widely represented by hydroxycinnamic acids $492.05 \mathrm{mg} /$ day $(88.5 \%$ of phenolic acids) and subsequently by hydroxybenzoic acids $64.22 \mathrm{mg} /$ day (11.5\%). Coffee was the major source of hydroxycinnamic acids $(71 \%)$, and tea was the main source of hydroxybenzoic acids $(93.5 \%)$.

In the case of the other groups of phenolic compounds, lignans amounted to $12.09 \mathrm{mg} /$ day ( $41.1 \%$ of lignans, stilbenes and other polyphenols), stilbenes to $0.18 \mathrm{mg} /$ day $(0.6 \%)$, and the other polyphenols to $17.14 \mathrm{mg} /$ day $(58.3 \%)$. The main dietary sources of lignans were cucumbers $(41.2 \%)$ and red cabbage (22.0\%), and the main sources of stilbenes were red currants (approximately $26 \%$ ), red wine $(24 \%)$, strawberries $(22 \%)$ and white wine $(16 \%)$. Dietary sources of other polyphenols were mostly whole meal rye bread $(60 \%)$ and coffee $(24 \%)$.

\section{Discussion}

As it was shown by the studies carried out in various research centers, the consumption of polyphenols may differ among populations, especially when values derived with different analytical methods are compared. Total polyphenol intake $989 \mathrm{mg} /$ day (expressed as aglycone equivalents) in the current study was less than this assessed with the total polyphenol assay. As we have shown in a previous study, the intake of polyphenols for this particular test group was 1031-1172 mg GAE (Gallic acid equivalents)/day, and was calculated on the basis of an own database of polyphenols, which were assessed with the Folin-Ciocalteu (FC) method [18]. As we expected, these discrepancies might have resulted mainly from the application of two different analytical methods of polyphenol determination (FC method vs. high pressure liquid chromatography (HPLC) method) as well as from minor shortcomings of polyphenol contents for particular food items in the searched databases. On the other hand, the FC method can give higher results due to the presence in food of non-phenolic substances, which can react with the FC reagent (FCR), including some vitamins, thiols and amino 
acids [19]. Therefore the FC method can only be considered as a rough measure of polyphenols for most foods [19]. Major disadvantage of the FC method is quantitative analysis only, but it does not give answers to the question what is the composition of polyphenols. In the present work, in addition to quantitative analysis, qualitative analysis was made, both of which used common databases.

Table 5. Dietary polyphenol intakes calculated with the Phenol-Explorer database and their major food contributors $(n=6661)$.

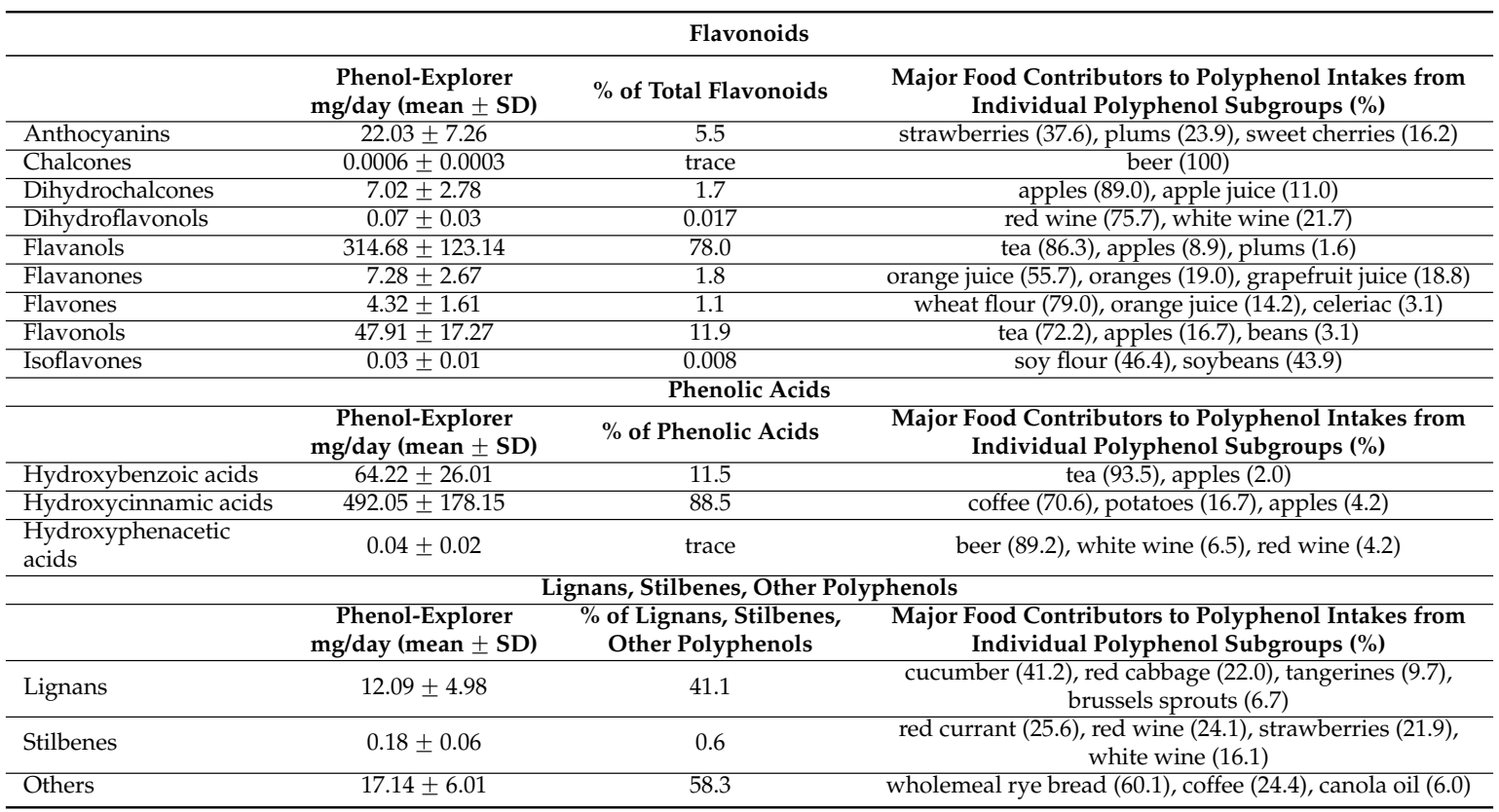

Substantially, the $989 \mathrm{mg} /$ day polyphenol intake estimated in this study for the Polish population was higher compared to polyphenol intakes estimated for the population of Greece, $744 \mathrm{mg} /$ day in men and $584 \mathrm{mg} /$ day in women [12], population of high cardiovascular risk in Spain $820 \mathrm{mg} /$ day [20] and Finland $863 \mathrm{mg} /$ day [21], but lower than the polyphenol intake in France at $1193 \mathrm{mg} /$ day [13] and in a Spanish population consuming the Mediterranean diet (1173 mg/day) [22]. As we have shown earlier, the consumption of phenolics may vary due to age and gender $[18,23]$. In our present study, the age range of the studied population was 20-74 years, while, for example, in French studies it was 45-60 years [13]. It is characteristic that older people tend to have reduced intakes of polyphenols compared with the younger age groups $[23,24]$. The intake of polyphenols in our study largely corresponds to various age groups of Poland's adult society, and involves elderly participants, which could be one of the supposed reasons for the reduced intake of polyphenols by the entire studied population.

A further consideration was the appropriate selection of the study groups taken for comparison. As some studies show, polyphenol intakes in general populations may differ from the intakes by communities [12]. This finding can be confirmed by our research. If we compare our data with other studies carried out regionally in Poland, we find that they may slightly vary. In the population of the city of Krakow, Poland, phenolic intake was $1092 \mathrm{mg} /$ day (calculated as aglycones) [24]. With the sum of polyphenols of $989 \mathrm{mg} /$ day, our results are just about $10 \%$ lower than in this urban population.

Flavonoids are a large class of polyphenols. Both data sources used in this study, the USDA databases and Phenol-Explorer, give the possibility to estimate flavonoid contents in the diet. The USDA tables provide data for six subclasses of flavonoids: anthocyanins, flavanols, flavanones, flavones, flavonols [8] and isoflavones [9]. In turn, Phenol-Explorer, in addition to the listed, provides data for the precursor flavonoid compounds, which are chalcones, dihydrochalcones and dihydroflavonols. We found that the intake of flavonoids by the study participants was about one 
third higher when calculated using the USDA databases in relation to the Phenol-Explorer database, $525 \mathrm{mg} /$ day vs. $404 \mathrm{mg} /$ day. The main reason for these discrepancies might be better characterization of tea flavonoids by the USDA database. However, Phenol-Explorer data of polyphenol contents are more complete regarding cereal products. Compared to other research, the results obtained on the basis of Phenol-Explorer were about one third lower than these of the urban Polish population $572 \mathrm{mg} /$ day (as aglycone equivalents), for which the results were calculated using the same method [24] and similar to the Spanish PREDIMED cohort $443 \mathrm{mg} /$ day [20].

In our study, the latest release of the USDA flavonoid database (2014) of five subclasses of flavonoids (anthocyanins, flavanols, flavanones, flavones, and flavonols) was used, which could affect the results of comparisons with populations in other studies, which used the earlier versions of the USDA flavonoid database. For example, in the European Prospective Investigation into Cancer and Nutrition (EPIC) study carried out in 2010 in Spain, the intake of flavonoids by the adult population aged 35-64 years amounted to $313 \mathrm{mg} /$ day [25]. Compared to this research, flavonoid intake in our study was more than $40 \%$ higher. However, it should be noted that the USDA flavonoid database used in the EPIC study was from 2007. Since then, it has been significantly upgraded with many new foods and new data concerning flavonoid contents. By comparing the sources of flavonoids for various populations, it can be concluded that they may differ depending on the preferences for specific types of food. In our study and in the US diet, they were mainly tea, $75.9 \%$ and $82.8 \%$ [26], respectively, while in Spain they were oranges, apples, and red wine [20].

In the case of the studied Polish population, intake of phenolic acids exceeds the intake of flavonoids, mainly due to the consumption of coffee, tea, potatoes and apples. Earlier studies found that phenolic acids are the main contributors to the total polyphenol intake in the non-Mediterranean countries, and they accounted for 57\% and 53\% polyphenol contribution depending on gender [12]. We observed a similar 56\% phenolic acid contribution. As in the Spanish Prevención con Dieta Mediterránea (PREDIMED) cohort study [20], hydroxycinnamic acids were main contributors to the total polyphenol intake in our study. However, they were only slightly exceeded by the intake of flavonoids from tea in our study.

In addition to flavonoids and phenolic acids, one source of polyphenols for the studied population was lignans. Cabbage and fruit vegetables are listed as primary sources of lignans for the European populations [27], which is also confirmed by the results of our research. Another minor phenolic compounds assessed in this study was stilbenes. These phenolics are particularly abundant in red wine, especially in the form of stilbenoid resveratrol. In the current research, red currant, red wine and strawberries almost equally contributed to the intake of stilbenes, from $\sim 22$ to $\sim 26 \%$ of the total stilbenes. In contrast to the intakes of lignans and stilbenes in other European regions, from 3.1 to $9.1 \mathrm{mg} /$ day [12], these intakes in the studied Polish population were much greater and accounted to $12.3 \mathrm{mg}$ /day, mainly due to the consumption of cucumbers and red cabbage, which are popular culinary vegetables in Poland.

According to Phenol-Explorer, non-alcoholic beverages accounted for $75 \%$ of dietary intake of polyphenols by the studied representative sample of the Polish population, and the tea for $76 \%$ intake of flavonoids, while coffee for $62 \%$ intake of phenolic acids. In addition, tea provided $37.0 \%$ polyphenols, and the coffee $35.5 \%$. Such results with regard to tea are not surprising, because Poland is a country of high tea consumption. With $1 \mathrm{~kg}$ per capita intake, Poland ranks fourth in Europe for tea consumption, and ninth worldwide [28]. As it was found in the studies involving populations of Mediterranean and non-Mediterranean countries, high contribution of coffee and tea to the polyphenol intake is typical for the non-Mediterranean countries [12]. However, in contrast to other non-Mediterranean countries [12], contribution of polyphenols from tea in our study was considerable, $37.0 \%$ vs. $17.0 \%$ in other countries. 


\section{Conclusions}

To the best of our knowledge this is the first attempt to estimate both the intake of polyphenols, including flavonoids, using the Phenol-Explorer database and the intake of flavonoids assessed with the latest release of the USDA database, in the representative sample of Poland's general population. This study found that tea is the primary source of polyphenols and flavonoids for the studied population, including mainly flavanols, while coffee is the most important contributor of phenolic acids, mostly hydroxycinnamic acids. Our study also demonstrated that flavonoid intakes estimated according to various databases might substantially differ. If there is a need to compare intakes of flavonoids between populations, the use of one database should be preferred. Presumably, the use of several combined databases can truly reflect the intake of flavonoids, but it will be difficult to make comparisons between populations for which only one method of calculation has been used. Therefore, further work should be undertaken to expand polyphenol databases to better reflect their food contents.

Acknowledgments: This research was supported by grants from the Medical University of Białystok, Poland.

Author Contributions: Anna M. Witkowska designed the study, coordinated funds for the project, performed literature review, analyzed the data and drafted the manuscript. Małgorzata E. Zujko coordinated funds for the project and critically reviewed the manuscript. Anna Waśkiewicz provided the data of the WOBASZ study and critically reviewed the manuscript. Katarzyna M. Terlikowska performed literature research and coordinated funds for the project. Walerian Piotrowski performed statistical calculations. All authors read and approved the final version of the paper.

Conflicts of Interest: The authors declare no conflicts of interest.

\section{References}

1. Pandey, K.B.; Rizvi, S.I. Plant polyphenols as dietary antioxidants in human health and disease. Oxid. Med. Cell. Longev. 2009, 2, 270-278. [CrossRef] [PubMed]

2. Manach, C.; Scalbert, A.; Morand, C.; Rémésy, C.; Jiménez, L. Polyphenols: Food sources and bioavailability. Am. J. Clin. Nutr. 2004, 79, 727-747. [PubMed]

3. Pérez-Jiménez, J.; Neveu, V.; Vos, F.; Scalbert, A. Systematic analysis of the content of 502 polyphenols in 452 foods and beverages: An application of the Phenol-Explorer database. J. Agric. Food. Chem. 2010, 58, 4959-4969. [CrossRef] [PubMed]

4. Yao, L.H.; Jiang, Y.M.; Shi, J.; Tomás-Barberán, F.A.; Datta, N.; Singanusong, R.; Chen, S.S. Flavonoids in food and their health benefits. Plant Foods Hum. Nutr. 2004, 59, 113-122. [CrossRef] [PubMed]

5. Balentine, D.A.; Dwyer, J.T.; Erdman, J.W.; Ferruzzi, M.G.; Gaine, P.C.; Harnly, J.M.; Kwik-Uribe, C.L. Recommendations on reporting requirements for flavonoids in research. Am. J. Clin. Nutr. 2015, 101, 1113-1125. [CrossRef] [PubMed]

6. Heleno, S.A.; Martins, A.; Queiroz, M.J.; Ferreira, I.C. Bioactivity of phenolic acids: Metabolites versus parent compounds: A review. Food Chem. 2015, 173, 501-513. [CrossRef] [PubMed]

7. Teixeira, J.; Gaspar, A.; Garrido, E.M.; Garrido, J.; Borges, F. Hydroxycinnamic acid antioxidants: An electrochemical overview. Biomed. Res. Int. 2013. [CrossRef] [PubMed]

8. Bhagwat, S.; Haytowitz, D.B.; Holden, J.M. USDA Database for the Flavonoid Content of Selected Foods. Release 3.1 (May 2014). Available online: https://data.nal.usda.gov/dataset/usda-databaseflavonoid-content-selected-foods-release-31-may-2014 (accessed on 13 January 2015).

9. Bhagwat, S.; Haytowitz, D.B.; Holden, J.M. USDA Database for the Isoflavone Content of Selected Foods Release 2.0. Available online: http://www.ars.usda.gov/SP2UserFiles/Place/80400525/ Data/isoflav/Isoflav_R2.pdf (accessed on 25 May 2015).

10. Phenol-Explorer. Database on polyphenol content in food. Available online: http://phenol-explorer.eu/ (accessed on 27 May 2015).

11. Neveu, V.; Perez-Jiménez, J.; Vos, F.; Crespy, V.; du Chaffaut, L.; Mennen, L.; Knox, C.; Eisner, R.; Cruz, J.; Wishart, D.; et al. Phenol-Explorer: An online comprehensive database on polyphenol contents in foods. Database (Oxf.) 2010. [CrossRef] [PubMed] 
12. Zamora-Ros, R.; Knaze, V.; Rothwell, J.A.; Hémon, B.; Moskal, A.; Overvad, K.; Tjønneland, A.; Kyrø, C.; Fagherazzi, G.; Boutron-Ruault, M.C.; et al. Dietary polyphenol intake in Europe: The European Prospective Investigation into Cancer and Nutrition (EPIC) study. Eur. J. Nutr. 2015. [CrossRef] [PubMed]

13. Pérez-Jiménez, J.; Fezeu, L.; Touvier, M.; Arnault, N.; Manach, C.; Hercberg, S.; Galan, P.; Scalbert, A. Dietary intake of 337 polyphenols in French adults. Am. J. Clin. Nutr. 2011, 93, 1220-1228. [CrossRef] [PubMed]

14. Broda, G.; Rywik, S. Multicenter national Polish population health status tests-WOBASZ project with defined problems and treatment goals. Kardiol. Pol. 2005, 63, 601-604.

15. Rywik, S.; Kupść, W.; Piotrowski, W.; Broda, G.; Piwoński, J.; Kurjata, P.; Waśkiewicz, A.; Gaździk, D. Multicenter national Polish population health status tests-WOBASZ project. Establishment of methods and logistics. Kardiol. Pol. 2005, 63, 605-613.

16. Zujko, M.E.; Witkowska, A.M.; Waśkiewicz, A.; Piotrowski, W.; Terlikowska, K.M. Dietary antioxidant capacity of the patients with cardiovascular disease in a cross-sectional study. Nutr. J. 2015, 14, 26. [CrossRef] [PubMed]

17. Kunachowicz, H.; Nadolna, I.; Przygoda, B.; Iwanow, K. Food Composition Tables; PZWL: Warsaw, Poland, 2005.

18. Zujko, M.E.; Witkowska, A.M.; Waśkiewicz, A.; Sygnowska, E. Estimation of dietary intake and patterns of polyphenol consumption in Polish adult population. Adv. Med. Sci. 2012, 57, 375-384. [CrossRef] [PubMed]

19. Everette, J.D.; Bryant, Q.M.; Green, A.M.; Abbey, Y.A.; Wangila, G.W.; Walker, R.B. Thorough study of reactivity of various compound classes toward the Folin-Ciocalteu reagent. J. Agric. Food Chem. 2010, 58, 8139-8144. [CrossRef] [PubMed]

20. Tresserra-Rimbau, A.; Medina-Remón, A.; Pérez-Jiménez, J.; Martínez-González, M.A.; Covas, M.I.; Corella, D.; Salas-Salvadó, J.; Gómez-Gracia, E.; Lapetra, J.; Arós, F.; et al. Dietary intake and major food sources of polyphenols in a Spanish population at high cardiovascular risk: The PREDIMED study. Nutr. Metab. Cardiovasc. Dis. 2013, 23, 953-959. [CrossRef] [PubMed]

21. Ovaskainen, M.L.; Törrönen, R.; Koponen, J.M.; Sinkko, H.; Hellström, J.; Reinivuo, H.; Mattila, P. Dietary intake and major food sources of polyphenols in Finnish adults. J. Nutr. 2008, 138, 562-566. [PubMed]

22. Saura-Calixto, F.; Goñi, I. Antioxidant capacity of the Spanish Mediterranean diet. Food Chem. 2006, 94, 442-447. [CrossRef]

23. Zujko, M.E.; Witkowska, A.M.; Waśkiewicz, A.; Mirończuk-Chodakowska, I. Dietary antioxidant and flavonoid intakes are reduced in the elderly. Oxid. Med. Cell. Longev. 2015. [CrossRef] [PubMed]

24. Grosso, G.; Stepaniak, U.; Topor-Mądry, R.; Szafraniec, K.; Pająk, A. Estimated dietary intake and major food sources of polyphenols in the Polish arm of the HAPIEE study. Nutrition 2014, 30, 1398-1403. [CrossRef] [PubMed]

25. Zamora-Ros, R.; Andres-Lacueva, C.; Lamuela-Raventós, R.M.; Berenguer, T.; Jakszyn, P.; Barricarte, A.; Ardanaz, E.; Amiano, P.; Dorronsoro, M.; Larrañaga, N.; et al. Estimation of dietary sources and flavonoid intake in a Spanish adult population (EPIC-Spain). J. Am. Diet. Assoc. 2010, 110, 390-398. [CrossRef] [PubMed]

26. Song, W.O.; Chun, O.K. Tea is the major source of flavan-3-ol and flavonol in the U.S. diet. J. Nutr. 2008, 138, 1543S-1547S. [PubMed]

27. Tetens, I.; Turrini, A.; Tapanainen, H.; Christensen, T.; Lampe, J.W.; Fagt, S.; Håkansson, N.; Lundquist, A.; Hallund, J.; Valsta, L.M.; et al. Dietary intake and main sources of plant lignans in five European countries. Food Nutr. Res. 2013, 57. [CrossRef] [PubMed]

28. Ministry of Treasury Republic of Poland. State of the Polish tea market. Available online: http:/ / www.msp.gov.pl/en/polish-economy/economic-news/5676,State-of-the-Polish-tea-market.html (accessed on 27 May 2015).

(C) 2015 by the authors; licensee MDPI, Basel, Switzerland. This article is an open access article distributed under the terms and conditions of the Creative Commons by Attribution (CC-BY) license (http://creativecommons.org/licenses/by/4.0/). 